\title{
Systemic principles of value co-creation: Synergetics of value and service ecosystems
}

\author{
Timo Meynhardt ${ }^{\mathrm{a}, \mathrm{b}, *}$, Jennifer D. Chandler ${ }^{\mathrm{c}}$, Pepe Strathoff ${ }^{\mathrm{b}}$ \\ ${ }^{a}$ Dr. Arend Oetker Chair of Business Psychology E Leadership, HHL Leipzig Graduate School of Management, Jahnallee 59, 04109 Leipzig, Germany \\ b Center for Leadership and Values in Society, University of St. Gallen, Dufourstrasse 40a, 9000 St. Gallen, Switzerland

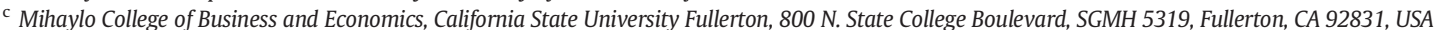

\section{A R T I C L E I N F O}

\section{Article history:}

Received 1 August 2015

Received in revised form 1 January 2016

Accepted 1 February 2016

Available online 29 March 2016

\section{Keywords:}

Value co-creation

Service ecosystems

Self-organization

Service-dominant logic

Synergetics

Public value

\begin{abstract}
A B S T R A C T
While most investigations of value and value co-creation empirically focus on either the individual micro-level or the collective macro-level, a systemic perspective asserts that investigations at one level, in isolation from the other, are incomplete. Based on synergetics and its core principles of emergence and enslavement (consensualization), we argue that value is a systemic property (i.e. an order parameter) that emerges from micro-macro links in service ecosystems. We propose a framework that begins to unravel the complexity of value co-creation and the dynamics of service ecosystem evolution. We introduce nine systemic principles of value co-creation: critical distance, stability, amplification, internal determination, nonlinearity and feedback, phase transitions, symmetry-breaking, limited predictability, and historical dependence. Based on these, we outline future research opportunities in three areas: the moralization of markets, an acceleration of societal dynamics, and the increasing embeddedness of service in society.
\end{abstract}

(c) 2016 Elsevier Inc. All rights reserved.

\section{Introduction}

Although there has been a surge of research on value co-creation in recent years, the direct topic of value has not received equal empirical attention, perhaps because value is inherently and implicitly present in any study that investigates satisfaction, profit, or firm performance (Grönroos \& Voima, 2013). This includes studies that for instance emphasize value-creating practices (Kjellberg \& Helgesson, 2006; Schau, Muniz, \& Arnould, 2009), value co-creation and co-production processes (Etgar, 2008; Payne, Storbacka, \& Frow, 2008), value networks (Lusch, Vargo, \& Tanniru, 2010), and value propositions (Frow \& Payne, 2011; Chandler \& Lusch, 2015).

Fortunately, extant literature on service ecosystems has given some form and substance to the study of value. The service-dominant logic (SDL) literature places value at the center of service ecosystems, or systems of resource-integrating actors (Lusch \& Vargo, 2014), in which actors are joined by value and, specifically, mutual value co-creation efforts (Vargo \& Lusch, 2011). Societal megatrends such as a moralization of the markets (Stehr, 2007), an acceleration of society (Rosa, 2005), and an increasing awareness of the social embeddedness of economic actions (Granovetter, 1985) emphasize mutuality in social

\footnotetext{
* Corresponding author at: Dr. Arend Oetker Chair of Business Psychology \& Leadership, HHL Leipzig Graduate School of Management, Jahnallee 59, 04109 Leipzig, Germany. Tel.: + 491711717736 (mobile).

E-mail addresses: timo.meynhardt@hhl.de (T. Meynhardt), jechandler@fullerton.edu (J.D. Chandler), pepe.strathoff@unisg.ch (P. Strathoff).
}

systems, underlining the need for a systemic approach that considers the dynamic properties of value co-creation.

Based on this, our proposed framework conceptualizes value as a core organizing principle-or, what synergetics calls an order parameter-of service ecosystems. Because value is simultaneously an individual and collective phenomenon, it is important to study value at the micro-level, meso-level, and macro-level of a service ecosystem (Chandler \& Vargo, 2011). To do this, we go beyond a network perspective that is rather static, to focus on the dynamic aspects of system behavior across these levels (Lusch \& Vargo, 2014; Haase \& Pick, 2015). Because value cannot be separated from either the individual microlevel (e.g. customer value) or the collective macro-level (e.g. public value), it is necessary to develop a theoretical foundation for exploring the systemic nature of value and value co-creation (Prahalad \& Ramaswamy, 2004; Lusch \& Vargo, 2006).

This is not to say that investigations of value and value co-creation at either the individual micro-level or the collective macro-level perspectives are incorrect; but a systemic perspective would view each of these perspectives, in isolation from the other, as incomplete (Pires, Dean, \& Rehman, 2014). We emphasize that value-as a systemic property-cannot be reduced to the individual or the collective level. Although this has been acknowledged from the service ecosystems perspective (Chandler \& Vargo, 2011), there has not yet been a comprehensive framework that accounts for dynamic multilevel systems from an SDL perspective. As a result, it is difficult to systematically assess and operationalize the (self-organized) workings of service ecosystems. Current theoretical "tools" are insufficient for opening up the black box "system" and clarifying its behavior. This leads us to the following 
research question: What are the systemic principles of value co-creation in service ecosystems?

We seek to contribute to the ongoing debate regarding value and value co-creation within service ecosystems by drawing on selforganization theory, namely synergetics, to catalyze a dynamic perspective on value as a systemic property (Haken, 1977, 1984, 1993). The theory of synergetics, as developed by Hermann Haken (Haken, 1977; Haken \& Schiepek, 2005), can help us to explain how individual experience (e.g. customer value) interacts with collective phenomena (e.g. public value). Based on the idea of formalizing micro-macro links (Alexander, Giesen, Münch, \& Smelser, 1987) in a system, the synergetics perspective formally articulates when and how a system order changes in a self-organized way. Synergetics asserts that relatively stable macroscopic states tend to emerge out of complex systems of interacting parts. In turn, these order parameters inform how the parts abide by the rules of the game (enslaving or consensualization). Its independence from a particular (social) scientific discipline makes synergetics a suitable formalized apparatus for inquiry to the dynamic properties of system behavior (Meynhardt, 2004).

Based on the core synergetic processes of emergence and enslavement, ${ }^{1}$ we introduce nine systemic principles of value cocreation: critical distance, stability, amplification, internal determination, nonlinearity and feedback, phase transitions, symmetry-breaking, limited predictability, and historical dependence. These principles clarify the sensing and collating nature of value co-creation when viewed from a systems perspective (Lusch et al., 2010). They begin to shed light on the complexity of service that has recently become salient because intersections between the micro-level of value and macro-level of value have blurred lines among the traditional tasks, roles, and responsibilities of customers and firms (Jaakkola \& Alexander, 2014; Piller, Moeslein, \& Stotko, 2004; Schau et al., 2009).

The paper is structured as follows. We explore the origins of the service ecosystems concept, emphasizing how value has been conceptualized within service ecosystems. We then explain how synergetics can help to clarify value as a systemic property, and explain the nine systemic principles of value co-creation. Subsequently, we provide illustrative examples of how a synergetics approach can further our understanding of current phenomena that alter the context in which value cocreation processes take place. We end with a discussion of theoretical and practical implications.

\section{Conceptual background}

\subsection{Service ecosystems}

The service-dominant (SD) logic of value creation emphasizes knowledge and skills as primary resources for exchange (Vargo \& Lusch, 2004, 2008). By doing so, SD logic emphasizes the activities and processes of value co-creation, rather than its outputs and outcomes. According to SD logic, these activities and processes are catalyzed by service-the application of competences for the benefit of others (Vargo \& Lusch, 2004, 2008). This intertwines an actor's competences with the other actors' knowledge, skills, and competences (Vargo \& Lusch, 2016). As a result, these actors are joined together by service and their behaviors synchronize with wider market norms and expectations (Akaka, Vargo, \& Schau, 2015). Because of this, a service ecosystem, or a "relatively self-contained, self-adjusting system of resourceintegrating actors connected by shared institutional logics and mutual value creation through service exchange" emerges (Lusch \& Vargo, 2014, p. 161). Actors are thus joined because of mutual value cocreation efforts, and the actors together constitute a self-adjusting, self-contained service ecosystem.

\footnotetext{
1 Enslavement is the technical term used in the synergetics literature for processes of top-down ordering of the system according to the order parameter. Another term for this phenomenon is consensualization.
}

Viewing service in this way, we can begin to clarify the mechanisms of self-organizing, complex, and adaptive systems because of the "multiple interrelated actors, processes and systems that together move through phases and cycles" in service ecosystems (Chandler \& Lusch, 2015, p. 15). As these different processes and actors jointly evolve over time, they effect change on one another in nonlinear and dynamic ways. As a result, some service ecosystems thrive, while others wither away (Vargo, Maglio, \& Akaka, 2008). To advance the SDL literature, the proposed systems-level theory offers some explanation about why and how this occurs.

\subsection{Value and value co-creation}

We draw attention to value as a core organizing principle, or systemic property, of a service ecosystem. Value binds together different systemic parts in a coherent way (Edvardsson, Tronvoll, \& Gruber, 2011). As a systemic property, value cannot be understood by focusing only on a single component or level of a service ecosystem (Corsaro, 2014; Akaka, Vargo, \& Lusch, 2013). It often involves large, expansive networks of actors (Tax, McCutcheon, \& Wilkinson, 2013). Because value is simultaneously an individual and a collective phenomenon, the micro, meso, and macro levels of a service ecosystem characterize its emergence (Xie, Bagozzi, \& Troye, 2008; Chandler \& Vargo, 2011).

For these reasons, it is important to study value as unique to the service ecosystem and context in which it emerges, as well as to the actor for whom it emerges. The micro individual level of value is not isolated from a macro collective level of value. The micro-level is embedded within a meso-level, which is itself embedded simultaneously in a macrolevel (Chandler \& Vargo, 2011). The meso-level focuses on a collective, intersection, or relationship of an individual, while the micro-level focuses on the individual, and the macro-level focuses on the environment in which the meso-level and the micro-level exist. Thus, the meso-level points attention to ecosystem subsystems that interconnect micro-levels and macro-levels of value (Pires et al., 2014).

These parts contribute holistically to the whole. The study of one level without the other would be akin to for instance studying the value of the human eye (micro-level) without studying the optic nerve and the brain's ability (meso-level) to translate signals into meaningful information for the body (macro-level). The value of the human eye cannot be fully understood by simply looking at the parts it is composed of (iris, pupil, ocular lens, etc.). Rather, if we are to make sense of the eye and understand its value, we need to look at it as part of our complex visual and cognitive system.

Similarly, the disparate elements of a service ecosystem make more sense when they are viewed as synergistic parts of a whole, especially concerning value. Any individual actor that experiences value does so in a specific context while, conversely, value that is realized in a specific context can be shared by an individual in that context. Thus, the mutual constitution of individuals and their contexts makes it difficult to study value as extracted from one level vs. another (Giddens, 1984).

\section{A synergetics perspective of value co-creation}

\subsection{What is synergetics?}

To explore the dynamic interplay between individual and collective value, we draw on the synergetics literature. Synergetics furthers our understanding of how value emerges as an order parameter, and offers principles that clarify how bottom-up emergences and top-down enslavement unfold in service ecosystems (Ebeling \& Feistel, 1994; Meynhardt, 2004). Synergetics is based in the natural sciences but has also been applied to other disciplines such as management, economics, and psychology (Haken \& Mikhailov, 1993; Haken \& Schiepek, 2005). It offers principles that cannot be found in other theories, such as autopoiesis by Maturana and Varela (1987), describing self-reproduction of organisms, or Giddens' (1984) structuration theory, with its focus on 
the interplay between action and structure, or Weick's (1995) concept of sensemaking. While these theoretical approaches emphasize nonmechanistic processes and phenomena that elude linear causalities, only synergetics offers a formal approach that explains when and how a system's order changes in a self-organized fashion. According to synergetics, order parameters inform and define how the parts of a system abide by the rules of the game through processes of enslaving or consensualization, as we will explain below (Meynhardt, 2004).

We begin by asserting that value is situated in the social environment of a market object and a subject's appraisal of the object. On the one hand, viewing value in this way emphasizes the recent conceptualization of service experience that establishes a role for service in shaping collective value beyond an economic transaction (Meynhardt, 2009, 2015). The idea is that a third-party (often a firm) can influence the service experience so as to influence a subject's appraisal of an object. On the other hand, this perspective also underscores the unpredictable individual psychological process of valuing (Eagly \& Chaiken, 1993). The emphasis is on individual engagement in value co-creation, which can range from a literal, physical, or emotional involvement to the conscious shaping of context to enable certain experiences (Chandler \& Lusch, 2015). Owing to this mechanism for engagement, individual actors often become integrative mechanisms of larger value co-creation systems (Brodie, Hollebeek, Juric, \& Ilic, 2011).

As Vargo and Lusch argue, "co-creation of value is not an option" (2009, p. 9). Thus, it is necessary to explore the distinction between objectivist and subjectivist views of value. Value objectivists basically argue that value is; in other words, they argue that value is a characteristic of an object, embedded in matter, almost physically attached to it. This view implies that value exists regardless of somebody valuing and thus leads to the question how value can be identified and experienced (Dworkin, 2011). However, value subjectivists basically argue that something has a value - that value is not determined as an external entity or truth but is agreed upon through evaluation. This view emphasizes the roles of individual actors in identifying, realizing, and creating value while processing information and experiences. The language of being vs. having value to describe the positions of value objectivists and value subjectivists has been used by Heyde (1926).

Attempting to reconcile the objectivist and subjectivist views, Heyde (1926) highlights the location of value and the process of human appraisal that occurs within particular relationships and social contexts. Value is seen to emerge from a relationship between an object and a subject who is valuing the object. Value does not exist independently of this relationship. Value is thus an emergent order parameter that is based on a relationship; it requires subjects to relate to, or value, an object(s) in order for value to exist. Through the act of valuation (i.e. evaluation), value comes into being as an emergent phenomenon.

Because service triggers relationships, and these relationships form the context in which value emerges (ecosystem), value is not a separate entity with its own ontological status. By focusing on value as an order parameter, system analysis need not rely on a detailed analysis of the parts of a service ecosystem (firm behavior, individual consumers, etc.) (Ebeling \& Feistel, 1994; Meynhardt, 2004). Rather, focusing on value as an order parameter can help one to compress complex information about service ecosystems by revealing the quality of the system as a whole. In other words, clarification regarding the location and nature of value (i.e. the nature of relationships among individuals and parts) are at the heart of understanding a system.

Relationships and the individual parts they connect constitute service ecosystems. Service ecosystems include relationships that mediate how individual experiences intersect with societal norms and/or market trends. Desires, needs and evaluative efforts are not independent from the service ecosystems or the social contexts in which they occur. Thus, concerning value co-creation in service ecosystems, synergetics outlines a perspective that accounts for multilevel interactions. As illustrated in Fig. 1, systemic (macro-level) properties emerge from the interactions of a system's parts (micro-level) (Haken, 1977, 1984,
1993). This often follows a nonlinear process that is catalyzed when the system is destabilized from its old state. Synergetics asserts that fluctuations from state to state occur until, finally, a coherent new macroscopic state takes hold (see Fig. 1, on the left). These order parameters exist as long living systems that enslave short living systems (the parts), influencing them to abide by the rules of the game (Haken, 1984) (see Fig. 1, on the right). The interplay between emergence and enslaving is a central tenet of the approach (circular causality).

Because of this, the micro-macro link is important, because it is the mechanism upon which the ordering of a service ecosystem can emerge, change, or solidify. Such micro-macro links can often be captured as relationships. As shown in Fig. 1, circular causality occurs when micro-level elements (individuals, groups, etc.) interact; this catalyzes emergences of macro-level properties (e.g. shared worldviews, norms, values in context). It is not one element or the other that gives rise to an emergence; rather, it is the relationships-and the relationships among the relationships-between the elements (and the elements themselves) that give rise to emergences. Over time, these emergent patterns (order parameters) gradually give order to-and, in some cases-coordinate most micro-level elements. Generally, they provide the system with coherence and orientation. The macro-level properties can enslave a system's elements (see Fig. 1), because the micro-level elements cannot escape these systemic properties. This is because a solid logic enmeshed in mutual, systemic value co-creation efforts binds the elements to the system. Elements that do not adhere to this logic fall away from the system, while elements that adhere to the logic are strongly attracted to the system.

In these ways, micro-macro links provide a fundamental mechanism for self-organization in service ecosystems. Macro-level properties emerge from micro-level interactions in ways that are not determined by any single element in the system. Yet, interestingly, changes in macro-level properties can also stimulate change in micro-level elements. Once firmly established, macro-level properties can enslave micro-level elements and, when this occurs, such properties can be referred to as order parameters (e.g. a trend, a collective preference, a cultural norm or attitude). These systemic properties are emergent, i.e. they are qualitatively different from a mere sum of the parts. They form a gestalt that cannot be discovered by simply looking at the parts and adding them up.

Based on this, as Meynhardt (2004) explains, micro-level value and macro-level value ${ }^{2}$ are related in the following ways. At the microlevel, psychological processes form elements (e.g. motivation, emotion, affect, etc.) in the system. If an evaluation of a product or service is perceived as a positive contribution to one's own basic needs (fulfilment/ satisfaction), value is created. The current order parameter is stabilized. However, if there is a negative (conscious or not) evaluation, various psychological mechanisms accommodate it (e.g. distortion, denial). Past experience is questioned, established practices and routines no longer work-and an actor may for instance feel psychological discomfort (Festinger, 1957). In such situations, the system might be destabilized to a point where elements can 'break free' of an 'old order', and a 'new order' parameter can emerge (see Fig. 1, on the left). However, the main point is that the system stabilizes the new order via feedback to individual actors (Fig. 1, on the right). In this circular process of bottom-up emergence and top-down consensualization (enslavement), the partstogether-lead to a collective, systemic property-that is, a systemic emergence arises. This is shown in Fig. 1.

Order parameters only change when a system is critically destabilized (e.g. a massive loss of trust or a frame-breaking experience). But once the old order is critically challenged (bifurcation points), the system behavior becomes largely unpredictable. Different emergent order parameters may compete with each other or stabilize each other, such that the system oscillates between different states until a new equilibrium is

\footnotetext{
${ }^{2}$ For a detailed description of emotional self-organization and different views in psychology, for instance on unconscious and conscious evaluations, see Meynhardt, 2004.
} 

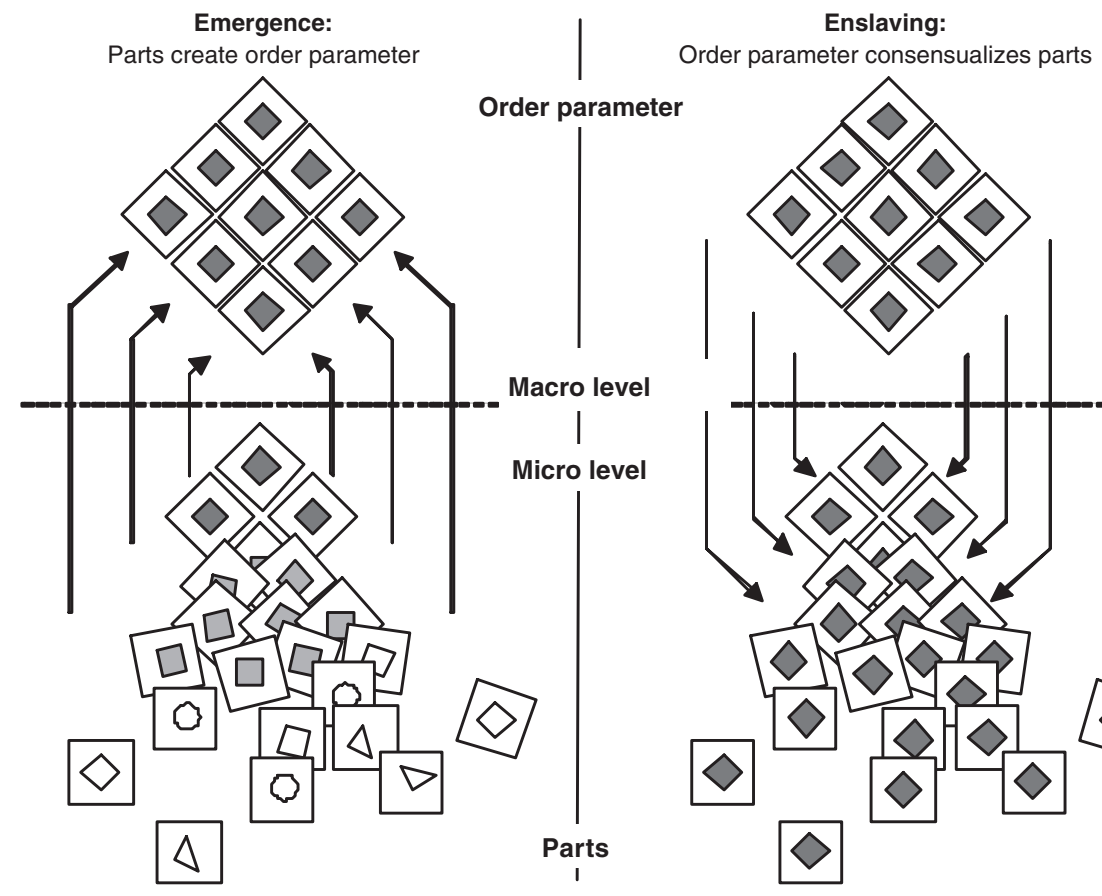

Order parameter consensualizes parts

Fig. 1. The principle of order parameter (adapted from Meynhardt, 2004, p. 84).

achieved. If a certain mode of value co-creation loses its function as the order parameter in a service ecosystem (e.g. the traditional cab ride for inner city transportation), it might for a while be unclear what the new mode of value co-creation would look like (e.g. car-sharing vs. ridesharing vs. public transport). In such systemic states where an order parameter has been destabilized and a new one has not yet been established, there is much space for diversity and the coexistence of competing order parameters. Very small fluctuations and interactions can then exert large consequences as they might push a system over a tipping point, after which a certain new order parameter can emerge and can dominate the system. In the following paragraph, we take a closer look at a number of principles that provide a more detailed understanding of service ecosystem behavior and value co-creation.

\subsection{Systemic principles of value co-creation}

Based on synergetics and its core processes of emergence and enslavement, we propose nine systemic principles of value co-creation in service ecosystems: critical distance, stability, amplification, internal determination, nonlinearity and feedback, phase transitions, symmetrybreaking, limited predictability, and historical dependence. As shown in Table 1, these are based on work by Ebeling and Feistel (1994).

Each systemic principle is detailed below and illustrated with an aspect of the failed introduction of New Coke in 1985. This move was an attempt by Coca-Cola to replace its existing original soft drink with a similar but even sweeter product in order to stop the rise of its competitor Pepsi. The new product fared very well in consumer research and a vast majority of subjects preferred it over both the original recipe Coke and Pepsi in blind tests. However, when the new product was introduced in April 1985, replacing the original one, consumers were outraged that 'the real thing' was removed from the market. Sales plummeted, and Coca-Cola was caught by surprise by the public's passion for its original product. In July 1985, the company reintroduced the original Coca-Cola. ${ }^{3}$

\footnotetext{
${ }^{3}$ For a more detailed account, see www.marketing91.com/coca-cola-brand-failure.
}

\subsubsection{Systemic principle 1: critical distance}

Self-organization only occurs when a system is beyond its equilibrium-stable values can be challenged only under conditions of uncertainty and/or arousal. A stable service ecosystem (in equilibrium) has its own propensity to continue into the future on its unique trajectory. Value propositions can elicit new logics or orders of engagement only when a service ecosystem is in disequilibrium. The introduction of New Coke was a case in point: The system was in a very stable equilibrium, with the parts (the consumers) strongly attached to the order parameter of the original formula. Therefore, New Coke could not lead to a reorganization of the system.

\subsubsection{Systemic principle 2: stability}

System stability depends on the intensity of perturbations or disturbances; there is strong stability against small perturbations in systems that are in equilibrium. Thus, in stable environments, a system is relatively adverse to change. Based on this, established service ecosystems in stable environments adhere to the established logic. The introduction of new versions of Coke such as Diet Coke or caffeinefree Coke did not lead to strong systemic reactions, as the perturbations were too small. However, the introduction of New Coke along with the withdrawal of the existing product led to strong systemic reactions.

\subsubsection{Systemic principle 3: amplification}

In transition periods, there may be fluctuations among subsystems within a system; amplifications influence emergences. In service ecosystems, fluctuations can arise from new evaluations, trial-and-error, creative search processes, or new amplified modes. In the New Coke example, some negative customer reactions developed into outrage by people who regarded the 'real' Coca-Cola as part of their American identity. Even Fidel Castro stated his opinion by pointing out that New Coke was a symbol of American capitalism's decadence. When a small change in the sugar content of a soft drink triggers such reactions, we observe amplification dynamics. 
Table 1

Systemic principles of value co-creation.

\begin{tabular}{lll}
\hline Systemic principle & $\begin{array}{l}\text { Systems theory foundation } \\
\text { (based on Ebeling \& Feistel, 1994: 40) }\end{array}$ & Relevance for value co-creation in service ecosystems \\
\hline $\begin{array}{l}\text { Systemic principle 1: } \\
\text { Critical distance }\end{array}$ & $\begin{array}{l}\text { Self-organization only occurs if a system is } \\
\text { beyond its equilibrium; only under conditions } \\
\text { of uncertainty and/or arousal can stable values } \\
\text { be challenged. }\end{array}$ & $\begin{array}{l}\text { A stable service ecosystem (in equilibrium) has its own propensity to continue on its } \\
\text { unique trajectory into the future. Only when a service ecosystem is in disequilibrium } \\
\text { can value propositions elicit new logics or orders of engagement. Based on the systemic } \\
\text { principle of critical distance, value can be co-created by participating according to the } \\
\text { existing logic of the service ecosystem. }\end{array}$
\end{tabular}

Illustrative example: The New Coke formula was not attractive enough to critically challenge the original one.

$\begin{array}{ll}\text { Systemic principle 2: } & \text { System stability depends on the intensity of } \\ \text { Stability } & \text { perturbations; relative stability against small } \\ & \text { perturbations. In stable environments, a system } \\ & \text { is relatively reluctant to change. }\end{array}$

\begin{tabular}{ll}
\hline Systemic principle 3: & In transition periods, there may be fluctuations \\
Amplification & among subsystems within a system; amplifications \\
& influence emergences.
\end{tabular}

\begin{tabular}{ll}
\hline Systemic principle 4: & Emergences heavily depend on existing internal \\
Internal determination & parameters; they can never be solely injected into \\
& a system by an external force. Further, it is impossible \\
& to predict systemic reaction to external forces because \\
& of the internal stability.
\end{tabular}

Systemic principle 5: $\quad$ Self-organization requires nonlinear dynamics, Nonlinearity and feedback basically caused by feedback loops.

Established service ecosystems in stable environments adhere to the established logic. Based on the systemic principle of stability, value can be co-created by ensuring continuity of the service ecosystem.

Illustrative example: Versions of Coke such as Diet Coke, Caffeine-Free Coke could not destabilize the general appraisal, but New Coke led to reactions of systemic resistance.

In service ecosystems, fluctuations can arise from new evaluations, trial-and-error, creative search processes, and new amplified modes. Based on the systemic principle of amplification, value can be co-created by catalyzing emergences and making the optimal emergences more salient in the service ecosystem.

Illustrative example: Unexpected customer reactions were amplified without warning.

Service ecosystems have a stable logic that largely determines systemic emergences. Owing to this, the effects of external efforts to inject new parameters to an existing service ecosystem are generally unpredictable. Based on the systemic principle of internal determination, value can be co-created by allowing for emergences. Illustrative example: Without knowing the system with its parts and internal dynamics, isolated, classic market research may fail utterly. In the New Coke example, at the outset, success was predicted.

Service ecosystems facilitate (social) psychological internalization (i.e. the establishment of new subjective evaluations and preferences). Based on the systemic principle of nonlinearity and feedback, value can be co-created by seeking and understanding nonlinear dynamics in a service ecosystem.

Illustrative example: In the beginning, only $12 \%$ of tasters expressed dislike when testing New Coke. But during the process, this minority gained huge influence.

\begin{tabular}{cl}
\hline Systemic principle 6: & Processes of self-organization are analogous to \\
Phase transitions & phase transitions in equilibrium. A change in \\
& values (individually and collectively) is \\
& experienced as a transition from one stable state \\
& to another stable state.
\end{tabular}

\begin{tabular}{cl}
\hline Systemic principle 7: & New orders are realized only after an emergence \\
Symmetry-breaking & has become established as an order parameter.
\end{tabular}

Service ecosystems are dynamic, continuous, and ever-changing. Based on the systemic principle of phase transitions, value can be co-created by enhancing changes in a service ecosystem.

Illustrative example: A new order emerges in a process of synchronization until yet another equilibrium is achieved. This was not achieved with New Coke.

While emergences are at first unpredictable, over time, they become more established and can catalyze new order parameters for service systems. Based on the systemic principle of symmetry-breaking, value can be co-created by emphasizing a new order or logic in a service ecosystem.

Illustrative example: A new order could not be established, because the new recipe did not emerge as a systemic order parameter.

\begin{tabular}{ll}
\hline Systemic principle $8:$ & The result of irregular (chaotic) processes is not \\
Limited predictability & predictable beyond the short term.
\end{tabular}

The individual or social process of changing values cannot be predicted. Based on the systemic principle of limited predictability, value can be co-created by expecting changes in the long-term viability of a service ecosystem.

Illustrative example: See the list of New Coke resistance actions.

\begin{tabular}{cl}
\hline Systemic principle 9: & $\begin{array}{l}\text { A system can only be understood on the basis } \\
\text { of insight into its developmental history. }\end{array}$
\end{tabular}

To understand a certain system of subjective evaluations, one needs to know its history. A single connection or link between actors can seldom be understood by itself. Based on the systemic principle of historical dependence, value can be co-created by viewing the service ecosystem holistically and historically.

Illustrative example: In the Coke example, one needs to know the basic history. Coca-Cola has been around since 1886, and thus already had a long history by the time New Coke appeared in 1985.

\subsubsection{Systemic principle 4: internal determination \\ Emergences depend strongly on existing internal parameters; they can never be injected into a system by an external force. Further, it is im- possible to predict systemic reactions to external forces owing to sys- temic internal stability. Established service ecosystems have a stable}

internal logic that largely determines the emergence of order parameters. Because of this, the effects of external efforts to inject new parameters into an existing service ecosystem are generally unpredictable. With the introduction of New Coke, Coca-Cola attempted to externally determine an order parameter without knowing or appreciating the 
system's internal dynamics. It did not understand that the strong role of its brand in the eyes of the public was not due primarily to its taste, but to it being a symbol of American patriotism and originality. Thus, the market research, which relied on blind testing, led to erroneous predictions.

\subsubsection{Systemic principle 5: nonlinearity and feedback}

Self-organization follows nonlinear dynamics that are basically caused by feedback loops. This is one reason why, in complex systems, the macro-level is different from a summation of its micro-level parts (emergence). Service ecosystems facilitate (social) psychological internalization (i.e. the establishment of new subjective evaluations and preferences). Based on the systemic principle of nonlinearity and feedback, value can be co-created by seeking, understanding, and acting according to nonlinear dynamics in a service ecosystem. In the New Coke case, consumers, when asked individually, preferred the new formula over the old one. However, as a collective forming a public, they strongly objected to it, and the initial minority that refused New Coke gained huge influence.

\subsubsection{Systemic principle 6: phase transitions}

Processes of self-organization are analogous to phase transitions in equilibrium. A change in values (individually and collectively) is experienced as a transition from one stable state to another. Service ecosystems are dynamic, continuous, and ever-changing. Based on the systemic principle of phase transitions, value can be co-created by enhancing changes in a service ecosystem and embracing emerging equilibria. In the New Coke example, the system was destabilized away from equilibrium, but finally returned to the same equilibrium-the same stable state it was in before.

\subsubsection{Systemic principle 7: symmetry-breaking}

New orders are realized only after an emergence has become established as an order parameter. While emergences are unpredictable at first, over time, they become more established, and can catalyze new order parameters for service systems. The failed introduction of New Coke is an example of a case in which a new order could not be realized, since the new phenomenon (the New Coke recipe) could not be established as a systemic order parameter.

\subsubsection{Systemic principle 8: limited predictability}

The result of irregular (chaotic) processes is not predictable beyond the short term. The individual or social processes of changing values cannot be predicted. The fact that the predictions derived from consumer research proved entirely wrong and the variety and extent of resistance actions in the New Coke example underline the limited predictability of system behavior.

\subsubsection{Systemic principle 9: historical dependence}

A system can only be understood based on insight into its developmental history. To understand a certain system of subjective evaluations, one needs to know its history. A single connection or link between actors can seldom be understood by itself. In this sense, a complex system is unlike a board of chess, where all information relevant for future actions can be derived from the current position of the chessmen on the board. Many Americans' attachment to the original Coke recipe cannot be understood without considering the company and its product history since 1886 .

\section{Discussion}

\subsection{General discussion}

Our proposed framework deepens and develops the service ecosystems perspective by outlining dynamic mechanisms by which service ecosystems evolve. Based on synergetics and its core principles of emergence and enslavement, we introduced nine systemic principles of value co-creation: critical distance, stability, amplification, internal determination, nonlinearity and feedback, phase transitions, symmetrybreaking, limited predictability, and historical dependence. These principles clarify the complexity of value co-creation when viewed from a service ecosystems perspective.

Specifically, each of these principles can extend how service ecosystems are viewed and studied (as shown in Table 1). Each principle corresponds with a different stage of system evolution. For instance, according to the systemic principle of critical distance, a stable service ecosystem (in equilibrium) has its own propensity to continue on its unique trajectory into the future. This propensity entails that a service ecosystem in equilibrium does not easily adapt to new logics or orders of engagement. So, in these situations, value can be co-created by participating according to the service ecosystem's existing logic. Additionally, as outlined by the systemic principle of stability, established service ecosystems in stable environments are more likely to adhere to established logics. In these situations, value is co-created by ensuring continuity of the service ecosystem, as well as the status quo in its environment.

However, if systemic change is desired, or if it is observed, value is co-created in the system via the emergence of new order parameters. Such emergences arise from system-level fluctuations that radiate from different parts of the system-including new evaluations, trialand-error, creative search processes, or new amplified modes. Thus, based on the systemic principle of amplification, systemic change can arise from the magnification of potential emergences in a service ecosystem. However, outcomes of such efforts are difficult to predict, because-as asserted by the systemic principle of internal determination-most thriving service ecosystems resist external efforts to inject new order parameters. It is not that there will be an absence of an effect; rather, it is often the case that the effect cannot be easily determined or controlled. As a result, value is co-created by allowing space for emergences to mature.

When systems are already in disarray, value can order a service ecosystem according to the systemic principle of nonlinearity and feedback. Here, conventional cause-effect mechanisms are not as helpful to study as feedback loops (circular causality), which indicate which parts of service ecosystems drive the dynamic, continuous, and ever-changing nature of the system. For instance, a service ecosystem perspective views (social) psychological internalization (i.e. efforts to establish new evaluations or preferences) as a feedback loop that facilitates or inhibits change (i.e. that stabilizes the existing order). When old preferences diminish, new preferences may alter behaviors in the system, which-in turn-may change the nature of the system. The change(s) may not be immediately evident, and such efforts might require time and effort. What is important here is that a feedback loop catalyzed the change(s), which then altered the system's characteristics.

This points to the systemic principle of phase transitions. Because it is necessary to recognize the characteristics of a service ecosystem as it moves through time, it is important to recognize system evolution in stages. As noted, while emergences are at first unpredictable, over time, they become more established and recognizable. Eventually, they may catalyze new order parameters for a service ecosystem. Through this process, the system takes on new characteristics. According to the systemic principle of symmetry-breaking, value is co-created when a new order or logic in a service ecosystem enhances the system's vitality. This may influence individual or social processes of changing values, but cannot be controlled or predetermined-as asserted by the systemic principle of limited predictability. It is expected that change is constant and necessary to ensure the long-term viability of a service ecosystem. And, finally, to understand a system, one needs to know its history. A single connection or link between actors can seldom be understood by itself, much like a single photo taken during a motion picture can seldom capture the storyline and character development of a screenplay. Based on the systemic principle of historical dependence, a 
service ecosystem must be viewed holistically as uniquely determined by its idiosyncratic trajectory.

Every service ecosystem is unique and complex. As firms and customers become more integrated owing to technology and globalization, the context in which the nine systemic principles of value co-creation play out is also changing. To illustrate this, consider three areas of society that are undergoing significant transformation: the moralization of markets, an acceleration of societal dynamics, and the increasing embeddedness of service in society. From a synergetics perspective with a focus on service ecosystems, we can see these developments as changes in a system's control parameters. Control parameters are system-external factors that influence system behavior, but are not changed through the system. In physical systems, one might think of temperature or air pressure; in social systems such as service ecosystems, one can think of broader societal developments, such as the ones described below. Certainly, with another focus of enquiry or a higher aggregation level, these could also be conceptualized as order parameters within the system.

\subsection{Systemic value co-creation and the moralization of the markets}

First, according to Stehr (2007), global-level growth in prosperity, knowledge, and skills have contributed to a moralization of the markets, which refers to the influence that increased consumer politics, consciousness, and mindfulness have had and continue to have on market exchange. In other words, social norms, cultural world views, and non-economic interests have exerted more influence on contemporary markets than they did in yesteryear, when markets were more dominated by self-interest and mechanistic acquisition of money. This includes for instance a consciousness that is attached to the types and manners of service and production by firms; firms must now be more transparent in their manufacturing processes and market entry efforts and must ensure that these activities are ethical and socially responsible. At the same time, modern communication tools (e.g. social media such as Facebook, LinkedIn, or Twitter) have enabled customers and interest groups to gather and disseminate information among themselves; this leads to order parameters that can influence market moralization, because firms learn about consumer sentiment, perceptions, and attitudes via social media. These feedback loops render salient the demands made by 'political' or 'ethical' customers (e.g. Harrison, Newholm, \& Shaw, 2005). This has contributed to faster transitions between systemic states: a continuous moralization and re-moralization of markets according to amplified emergences.

However, it has become ever-more difficult for firms to focus on single and isolated stakeholders, especially when there may also be incompatible demands and interactions that are hard to analyze (Walsh, 2005). Too many diverging expectations, unknown preferences, and legitimacy issues make it almost impossible to engage uniformly with stakeholders (Phillips, 2003). The following research questions can be investigated: What are the factors that influence the timing and continuity of systemic transitions in moralized markets? Should an emergence be amplified? If so, when and how can an emergence be amplified? Are these principles characteristic of all service ecosystems? How can heterogeneous stakeholders be dealt with in moralized service ecosystems?

\subsection{Systemic value co-creation and the acceleration of society}

A trend of acceleration (Rosa, 2005) in modern society, characterized by high instability and change, calls for research into the orientation, adaptation, and learning capabilities at every level of a service ecosystem. Rosa (2005) argues for an increased need to 'coordinate' at the macro-level in order to reconcile the accelerated speed of economic processes, the pace of life, and the relentless chasing of social change. Publicly sensitive topics such as pollution, food quality, or medical progress concern society as a whole. At the micro-level, these topics manifest as anxieties, hopes, opinions, or perceived fairness, for instance, and can determine the evaluation of a product, service, or firm. This issue is even more salient since, owing to the increasing strength of business relative to government in terms of organizational and financial resources, more and more demands concerning the production of social goods are directed towards firms instead of the government (Moore \& Khagram, 2004). The following research questions can be investigated: What does systemic enslavement look like? What becomes of the elements of a system that fall away? How does the general acceleration of society impact on service ecosystems?

\subsection{Systemic value co-creation and social embeddedness}

Granovetter makes clear that "there is evidence all around us of the extent to which business relations are mixed up with social ones" (1985, p. 493). Similarly, Layton (2011) proposes that economic exchange is at all times embedded in an institutional, social, and cultural context. Service managers need to consider multiple stakeholders' perspectives. Value co-creation relationships extend beyond the traditional dyadic bonds (company-customer) that have been associated with exchange relationships (Vargo, 2009). The following research questions can be investigated: What are the best practices for cultivating system equilibrium? When a service ecosystem is thriving, how does a manager ensure its continuity? How are service ecosystems affected by social embeddedness?

\section{Implications}

\subsection{Research: the interplay between customer value and public value}

Value is a systemic property that exists at all levels of a service ecosystem, including the micro-level, meso-level, and macro-level. Against the background of co-creation, the moralized and accelerated society in which service is embedded cannot be addressed without controversy, because many different elements are simultaneously catalyzing emergences in a stable system; this illustrates the systemic principles of critical distance, stability, and amplification. This draws attention not just to immediate micro-level actors such as customers, but also to meso-level actors such as special interest groups, lobbyists, or socially conscious consumers as well as macro-level actors such as governments and institutions that may potentially want to disrupt established systems. Such disruption would illustrate the systemic principles of internal determination, nonlinearity and feedback, and phase transitions. If a firm cocreates value with a specific customer, but destroys value for all other actors in a system, it risks systemic disruption; micro-level value conflicts with macro-level values. The firm risks losing its license to operate. In this way, co-creation can lead to positive and negative value at the same time, thereby illustrating the systemic principles of symmetrybreaking, limited predictability, and historical dependence. An essential question here is the consistency between the firm's value proposition and its corporate strategy. The firm's core values and core purpose are defined in the corporate mission statement, and these should be ideally aligned with the external environment in which the firm competes in order for the service ecosystem to thrive.

Because value co-creation is a key characteristic of service ecosystems, the proposed framework shows how value as an order parameter can be better understood by employing a synergetics approach. If we take the co-creation perspective seriously and apply it to the link between micro-level and macro-level, we need to analyze its mutual impact and synergetic interplay. For instance, questions articulated at the macro-level (Meynhardt, 2009) can be worded for the micro-level using the criteria of customer value configuration (Belz \& Bieger, 2004, p. 101). Table 2 shows how micro-level customer value can be related to macro-level public value. Customer value propositions (left column) focus on delivering a particular product or service and experience to individual customers. This includes emotional aspects of a product, how well its use is explained, how high its quality is, and how cost- 
Table 2

Relationship between customer value and public value (after Meynhardt \& Stock, 2009, p. 56).

\begin{tabular}{|c|c|c|c|c|}
\hline \multirow{2}{*}{$\begin{array}{l}\text { Customer value } \\
\text { (focus on the individual) }\end{array}$} & \multicolumn{4}{|l|}{ Public value functions (focus on society) } \\
\hline & Ethical-moral & Political-social & Hedonistic-aesthetic & Instrumental-utilitarian \\
\hline $\begin{array}{l}\text { Emotion } \\
\text { Relationship } \\
\text { Explanation } \\
\text { Individualization } \\
\text { Relief/Security } \\
\text { Quality } \\
\text { Innovation } \\
\text { Cost-effectiveness } \\
\text { Speed } \\
\text { Coordination }\end{array}$ & $\begin{array}{l}\text { What type of acknowledgement } \\
\text { and valuation of the sense of } \\
\text { self-worth/identity do we want } \\
\text { to achieve through customer value? } \\
\text { - How much personal responsibility } \\
\text { do we want to remove from or } \\
\text { ascribe to the individual customer } \\
\text { through customer value? } \\
\text { - How do we justify dealing with } \\
\text { customers ethically in a } \\
\text { differentiated way? }\end{array}$ & $\begin{array}{l}\text { - What culture of interpersonal } \\
\text { contact do we want to promote } \\
\text { in realizing customer value? } \\
\text { - What interests of groups or } \\
\text { stakeholders in society will be } \\
\text { strengthened/weakened by the } \\
\text { customer value? } \\
\text { - What kind of social dialogue do } \\
\text { we want to conduct by } \\
\text { implementing individual } \\
\text { customer values? }\end{array}$ & $\begin{array}{l}\text { - What negative experiences do } \\
\text { we want to avoid through each } \\
\text { individual customer value? } \\
\text { - What positive experiences do we } \\
\text { want to promote through } \\
\text { customer value? } \\
\text { - What experiences among } \\
\text { noncustomers are we striving } \\
\text { for as a company or do we want } \\
\text { to avoid? }\end{array}$ & $\begin{array}{l}\text { - What is the basis of every } \\
\text { individual customer value } \\
\text { concerning facts and content? } \\
\text { - How is the use value for the } \\
\text { customer instrumental for a } \\
\text { functioning society? } \\
\text { - What standards of } \\
\text { problem-solving do we want } \\
\text { to set and determine through } \\
\text { every customer value? }\end{array}$ \\
\hline
\end{tabular}

effective it is for the customer (Belz \& Bieger, 2004). A public value perspective (columns 2 to 5 ) places the value proposition of a product or service into a societal context and asks what the properties of the customer value proposition mean for societal value dynamics and the value that individuals can derive from being part of a social collective. Accordingly, public value creation has been defined as "any impact on shared experience about the quality of the relationship between the individual and 'society' " (Meynhardt, 2009, p. 212). Table 2 contains exemplary questions to be asked from a public value perspective along the four public value dimensions (see Meynhardt, 2009, 2015). For instance, quality (e.g. food ingredients) as a customer value is placed into a broader context by asking how this value proposition affects society's functioning (e.g. the prevalence of obesity).

From a systems perspective, we argue that customer value and public value are linked in a synergetic interplay. This leads to a value proposition that links micro-level value and macro-level value in concrete terms-that is, the value proposition purposefully relates the microlevel, meso-level, and macro-level to one another. Thus, capitalizing on value dynamics requires a framework that explicates both chances and limits. Further research may conceptualize a co-creation relationship at different levels by applying synergetic ideas of order parameters' emerging/enslaving processes as well as ideas of phase transitions by applying the self-organization principles introduced above. It calls both approaches to better understand a system's history and context, and methodologies to identify emerging instability points or amplifications of certain states. It points in particular to process studies (Pentland, 1999) and the reconstruction of patterns and system properties (order parameters).

\subsection{Practice: identifying opportunities for co-creation}

Our research also has some implications for practice, especially for managers who continuously deal with that "unknown animal called society". Systemic principles such as nonlinearity, internal determination, and historical dependence call for the extensive collection of process data, in order to be able to spot early weak signals that might be harbingers of systemic change. The fact that service ecosystems are selforganizing and thus fairly resistant to external 'shocks' points to a humble attitude to attempts to change shared values in society. The New Coke example is a case in point. It demonstrates that attempts to manage against stable system logics are prone to fail. To be successful, managers need to accept the system dynamics as they are, but need to be able to spot irregularities in patterns that might destabilize the system. In such situations, their potential for successful interventions is multiplied, owing to amplification and feedback loop dynamics. However, these windows of opportunity, where quick and resolute actions have the potential to shape long-term trends, tend to be infrequent and temporary. This observation points again to managers' need for collecting on-time process data, in order to be able to take appropriate actions.
Increasing moralization of the markets as well as acceleration of and embeddedness in society have forced firms to face the question of the extent to which their products and services are perceived as valuable for the community beyond customer value. However, because examining all stakeholders in so many different ways would not be practical (Walsh, 2005), it is preferable to also reflect more abstractly on a societal level: value creation for the community legitimizes the entrepreneurial activity in the sense of a social basis of a transaction, while also serving as the basis for the many diversified characteristics of customer value. Thus, managers need to keep in mind that each cocreation of value has consequences both for the individual and the community.

\section{Conclusion}

Value co-creation should be described as a synergetic interplay between the levels of a service ecosystem, and this interplay can be better understood and structured with self-organization theory. As Mittelstaedt, Kilbourne, and Mittelstaedt (2006, p. 131) note: “[The] activities and actors of the marketplace cannot be understood fully without also understanding the interdependence of markets and marketing systems with other dimensions of civic life." So, service ecosystem research is based on phenomena at the intersection of marketing and society. This requires recognition of emergent phenomena in service ecosystems and their embeddedness, and of potentially unexpected social consequences owing to the complex interplay of individual and collective phenomena. This is the root of our unique contribution: By applying synergetics to questions of value co-creation at both the societal public value (macro) level and the individual customer value (micro) level, the proposed nine systemic principles help to bridge the micromacro gap (Domegan et al., 2012). Thus, value must be viewed as a systemic property, and value co-creation must be regarded as an organizing principle not only for service but also for society.

\section{Acknowledgment}

The authors thank Robert F. Lusch, who contributed to an earlier version of this manuscript.

\section{References}

Akaka, M. A., Vargo, S. L., \& Lusch, R. F. (2013). The Complexity of Context: A Service Ecosystems Approach for International Marketing. Journal of International Marketing, 21(4), 1-20.

Akaka, M. A., Vargo, S. L., \& Schau, H. J. (2015). The context of experience. Journal of Service Management, 26(2), 206-223.

Alexander, J. C., Giesen, B., Münch, R., \& Smelser, N. J. (1987). The Micro-Macro Link. Berkeley: University of California Press.

Belz, C., \& Bieger, T. (Eds.). (2004). Customer Value: Kundenvorteile schaffen Unternehmensvorteile. Frankfurt am Main: Redline Wirtschaft.

Brodie, R. J., Hollebeek, L., Juric, B., \& Ilic, A. (2011). Customer engagement: conceptual domain, fundamental propositions, and implications for research. Journal of Service Research, 14(3), 252-271. 
Chandler, J. D., \& Vargo, S. L. (2011). Contextualization and value-in-context: how context frames exchange. Marketing Theory, 11(1), 35-49.

Chandler, J. D., \& Lusch, R. F. (2015). Service systems: a broadened framework and research agenda on value propositions, engagement and service experience. Journal of Service Research, 18(1), 6-22.

Corsaro, D. (2014). The emergent role of value representation in managing business relationships. Industrial Marketing Management, 43(6), 985-995.

Domegan, C., Haase, M., Harris, K., van den Heuvel, W. -J., Kelleher, C., Maglio, P. P., ... Peñaloza, L. (2012). Value, values, symbols and outcomes. Marketing Theory, 12(2), 207-211.

Dworkin, R. (2011). Justice for Hedgehogs. Cambridge, MA: Harvard University Press.

Eagly, A., \& Chaiken, S. (1993). Psychology of Attitudes. Fort Worth, TX: Harcourt Brace Jovanovich College Publishers.

Ebeling, W., \& Feistel, R. (1994). Chaos und Kosmos. Prinzipien der Evolution. Heidelberg: Spektrum Akademischer Verlag.

Edvardsson, B., Tronvoll, B., \& Gruber, T. (2011). Expanding understanding of service exchange and value co-creation: a social construction approach. Journal of the Academy of Marketing Science, 39(2), 327-339.

Etgar, M. (2008). A descriptive model of the consumer co-production process. Journal of the Academy of Marketing Science, 36(1), 97-108.

Festinger, L. (1957). A Theory of Cognitive Dissonance. Stanford: Stanford University Press

Frow, P., \& Payne, A. (2011). A stakeholder perspective of the value propositions concept European Journal of Marketing, 45(1/2), 223-240.

Giddens, A. (1984). The Constitution of Society. Berkeley, CA: University of California Press.

Granovetter, M. S. (1985). Economic action and social structure. The problem of embeddedness. American Journal of Sociology, 91, 481-510.

Grönroos, C., \& Voima, P. (2013). Critical service logic: making sense of value creation and co-creation. Journal of the Academy of Marketing Science, 41(2), 133-150.

Haase, M., \& Pick, D. (2015). Value creation in sharing networks: towards a typology of sharing networks. In M. Bruhn, \& K. Hadwich (Eds.), Interaktive Wertschöpfung durch Dienstleistungen (pp. 439-468). Wiesbaden: Springer Fachmedien.

Haken, H. (1977). Synergetics: Nonequilibrium Phase Transition and Self-Organization in Physics, Chemistry and Biology. Berlin, Heidelberg, New York: Springer.

Haken, H. (1984). Can Synergetics Be of Use to Management Theory? Springer Series in Synergetics, 26, 33-41.

Haken, H. (1993). Synergetics as a Strategy to Cope with Complex Systems. Springer Series in Synergetics, 26, 5-11.

Haken, H., \& Mikhailov, A. (Eds.). (1993). Interdisciplinary Approaches to Nonlinear Complex Systems. Berlin: Springer-Verlag.

Haken, H., \& Schiepek, G. (2005). Synergetik in der Psychologie: Selbstorganisation verstehen und gestalten. Göttingen: Hogrefe.

Harrison, R., Newholm, T., \& Shaw, D. (Eds.). (2005). The Ethical Consumer. London: Sage.

Heyde, J. E. (1926). Wert. Eine Philosophische Grundlegung. Erfurt: Verlag Kurt Stenger

Jaakkola, Elina, \& Alexander, Matthew (2014). The role of customer engagement behavio in value co-creation: a service ecosystem perspective. Journal of Service Research, 17(3), 247-261.

Kjellberg, H., \& Helgesson, C. -F. (2006). Multiple versions of markets: multiplicity and performativity in market practice. Industrial Marketing Management, 35(7), 839-855.

Layton, R. (2011). Towards a theory of marketing systems. European Journal of Marketing, 45(1/2), 259-276.

Lusch, R. F., \& Vargo, S. L. (2006). Service-dominant logic: reactions, reflections and refinements. Marketing Theory, 6(3), 281-288.

Lusch, R. F., \& Vargo, S. L. (2014). Service-Dominant Logic-Premises, Perspectives, Possibilities Cambridge: Cambridge University Press.

Lusch, R. F., Vargo, S. L., \& Tanniru, M. (2010). Service, value networks and learning. Journal of the Academy of Marketing Science, 38(1), 19-31.

Maturana, H., \& Varela, F. (1987). Tree of Knowledge: Biological Roots of Human Understanding. Boston \& London: Shambhala.
Meynhardt, T. (2004). Wertwissen: Was Organisationen wirklich bewegt. Münster: Waxmann.

Meynhardt, T. (2009). Public value inside: what is public value creation? International Journal of Public Administration, 32(3/4), 192-219.

Meynhardt, T. (2015). Public Value - Turning a Conceptual Framework into a Scorecard. In J. M. Bryson, B. C. Crosby, \& L. Bloomberg (Eds.), Public Value and Public Administration (pp. 147-169). Georgetown University Press.

Meynhardt, T., \& Stock, R. A. (2009). Customer Value und Public Value. Der Kundennutzen im Bauch der Gesellschaft. Marketing Review St. Gallen, 1, 53-57.

Mittelstaedt, J. D., Kilbourne, W. E., \& Mittelstaedt, R. A. (2006). Macromarketing as agorology: macromarketing theory and the study of the agora. Journal of Macromarketing., 26(December), 131-142.

Moore, M., \& Khagram, S. (2004). On Creating Public Value. What Business Might Learn from Government about Strategic Management. Harvard Kennedy School Working Paper No. 3.

Payne, A., Storbacka, K., \& Frow, P. (2008). Managing the co-creation of value. Journal of the Academy of Marketing Science, 36(1), 83-96.

Pentland, B. T. (1999). Building process theory with narrative: from description to explanation. Academy of Management Review, 24(4), 711-724.

Phillips, R. A. (2003). Stakeholder legitimacy. Business Ethics Quarterly, 13, 25-41.

Piller, F. T., Moeslein, K., \& Stotko, Ch. M. (2004). Does mass customization pay? An economic approach to evaluate customer integration. Production Planning and Control, $15,435-444$.

Pires, G., Dean, A., \& Rehman, M. (2014). Using service logic to redefine exchange in terms of customer and supplier participation. Journal of Business Research, 68(5), 925-932.

Prahalad, C. K., \& Ramaswamy, V. (2004). Co-creation experiences: the next practice in value creation. Journal of Interactive Marketing, 18(3), 5-14.

Rosa, H. (2005). Beschleunigung-Die Veränderung der Zeitstrukturen in der Moderne. Frankfurt am Main: Suhrkamp.

Schau, H. J., Muniz, A. M., Jr., \& Arnould, E. J. (2009). How brand community practices create value. Journal of Marketing, 73(September), 30-51.

Stehr, N. (2007). Die Moralisierung der Märkte: Eine Gesellschaftstheorie. Frankfurt am Main: Suhrkamp.

Tax, S. S., McCutcheon, David, \& Wilkinson, Ian F. (2013). The service delivery network (SDN): a customer-centric perspective of the customer journey. Journal of Service Research, 16(November), 454-470.

Vargo, S. L. (2009). Toward a transcending conceptualization of relationship: a servicedominant logic perspective. Journal of Business \& Industrial Marketing, 24(5/6), 373-379.

Vargo, S. L., \& Lusch, R. F. (2004). Evolving to a new dominant logic for marketing. Journal of Marketing, 68(January), 1-17.

Vargo, S. L., \& Lusch, R. F. (2008). Service-dominant logic: continuing the evolution. Journal of the Academy of Marketing Science, 36(1), 1-10.

Vargo, S. L., \& Lusch, R. F. (2011). It's all B2B... and beyond: toward a systems perspective of the market. Industrial Marketing Management, 40(2), 181-187.

Vargo, S. L., \& Lusch, R. F. (2016). Institutions and axioms: an extension and update of service-dominant logic. Journal of the Academy of Marketing Science, 44(1), 5-23.

Vargo, S. L., Maglio, P. P., \& Akaka, M. A. (2008). On value and value co-creation: A service systems and service logic perspective. European Management Journal, 26(3), $145-152$.

Walsh, J. P. (2005). Book review essay: Taking stock of stakeholder management. Academy of Management Review, 30(2), 426-452.

Weick, K. (1995). Sensemaking in Organizations. Beverly Hills: Sage.

Xie, C., Bagozzi, R. P., \& Troye, S. V. (2008). Trying to prosume: toward a theory of consumers as co-creators of value. Journal of the Academy of Marketing Science, 36(1), 109-122. 